....

NASA Technical Memorandum 103750
$1 N-39$

3368

\title{
HITCAN for Actively Cooled Hot-Composite Thermostructural Analysis
}

CC. Chamis and P.L.N. Murthy

National Aeronautics and Space Administration

Lewis Research Center

Cleveland, Ohio

and

S.N. Singhal and J.J. Lackney

E. Suerdrup Technology, Inc.

1.ige Lewis Research Center Group

Brook Park, Ohio

Prepared for the

36th International Gas Turbine and Aeroengine Congress and Exposition sponsored by the American Society of Mechanical Engineers

Orlando, Florida, June 3-6, 1991 
HITCAN FOR ACTIVELY COOLED HOT-COMPOSITE THERMOSTRUCTURAL ANALYSIS

\author{
C.C. Chamis and P.L.N. Murthy \\ National Aeronautics and Space Administration \\ Lewis Research Center \\ Cleveland, Ohio $\mathbf{4 4 1 3 5}$ \\ S.N. Singhal and J.J. Lackney \\ Sverdrup Technology, Inc. \\ NASA Lewis Research Center \\ Brook Park, Ohio 44142
}

\title{
SUMMARY
}

A computer code, HITCAN (HIgh Temperature Composite ANalyzer) has been developed to analyze/design hot metal matrix composite structures. HITCAN is a general purpose code for predicting the global structural and local stress-atrain response of multilayered (arbitrarily oriented) metal matrix structures both at the constituent (fiber, matrix, and interphase) and the structure level and including the fabrication process effects. The thermomechanical properties of the constituents are considered to be nonlinearly dependent on several parameters including temperature, stress, and stress rate. The computational procedure employs an incremental iterative nonlinear approach utilizing a multifactor-interaction material behavior model, i.e., the material properties are expressed in terms of a product of several factors that affect the properties: HITCAN structural analysis capabilities (static, load stepping (a multistep static analysis with material properties updated at each step), modal, and buckling) for cooled hot structures are demonstrated through a specific example problem.

\section{INTRODUCTION}

High temperature metal matrix composites (HT-MMCs) have shown potential as structural materials for 21 st century propulsion systems. The thermomechanical properties of $\mathrm{HT}-\mathrm{MMCs}$ vary nonlinearly with respect to parameters such as temperature, stress, and stress rate. This nonlinear material behavior may alter the structural response significantly. Since experimental investigations are usually high in cost, computational models which include nonlinear material behavior simulating the real-life response of components made from HT-MMC materials are required.

The need for developing analysis models at all levels of composite construction (i.e., fiber/matrix/interphase, ply, laminate) for multilayered fibrous composites was recognized almost two decades ago. Based on this need, multilevel analysis computer codes have since been developed to computationally simulate multilayered fibrous composite behavior. Research related to various aspects of HT-MMC materials and structures has been conducted at the Lewis Research Center of the National Aeronautics and Space Administration (NASA) for several years. Building upon parts of this research effort, a high temperature composites analyzer code HITCAN, has been developed (ref. 1).

The objective of this paper is to summarize HITCAN's capabilities with a specific illugtrative example which demonstrates its application versatility and suitability for the thermostructural analysis of actively cooled hot structures. 


\section{HITCAN CAPABILITIES/DESCRIPTION}

HITCAN capabilities include prediction of global structural and local stressstrain response of multilayered high temperature metal matrix composite structures. It can also be used for modal and buckling analyses. Each layer of the composite can be of different material and can be arbitrarily oriented. The current version of the code can handle a large number of layers. HITCAN is primarily designed for metal matrix composites. However, it can be readily adapted for other composites as well.

In general, the analysis capabilities of HITCAN are primarily governed by those of its constituent module codes, MHOST (ref. 2), METCAN (ref. 3), and a dedicated mesh generator adapted from COBSTRAN (ref. 4).

MHOST is capable of handling standard two- and three-dimensional, beam, and shell finite elements, many types of boundary conditions, most types of loadings (e.g., concentrated, distributed, pressure, temperature, static, transient, cyclic, and impact), anisotropic composite materials, elastic and inelastic analyses, eigenvalue extraction for buckling and modal analyses. These capabilities have been demonstrated for various types of structures (such as beam, plate, ring, curved panel, and built-up structures - 1.e., structures made of a combination of several different types of geometries). METCAN is capable of modeling thermomechanical properties as multifactor-interaction functions of temperature, stress, and stress rate, etc. METCAN treats material nonlinearly at the constituent level. COBSTRAN is capable of modeling both linear and curved geometries using cubic spline interpolators in rectilinear coordinates.

A special feature of HITCAN is itg dedicated data base for available fiber/ matrix/interphase constituents of current interest to hot structures applications. The user needs to specify only a code name of the constituents input. HITCAN automatically searches, selects, and updates the appropriate properties from its database. A list of materials and their properties for the materials coded in the HITCAN database can be found in reference 3 . The database includes graphite, boron, silicon carbide, and tungsten fibers, and aluminum, titanium, copper, magnesium, and beryllium matrix materials.

The current version of HITCAN includes most (but not all) features of MHOST and METCAN. Work is continuing on including more features into HITCAN. Table I 1ists HITCAN features. The features that have been demonstrated through example problems in reference 1 are marked "tested" in italic letters in table I. Although the enhancement of the code continues, in its current form, it is applicable to a wide variety of composite thermostructural analysis problems.

The source code HITCAN consists of about 10000 FORTRAN statements. The accompanying codes METCAN and MHOST are comprised of about 7000 and 50 000 statements, respectively. Complete documentation of HITCAN including theoretical developments, user's manual, and demonstration manual are expected to be available in the near future. Figure 1 shows the approach used by HITCAN for analyzing composite structures. The left part of figure 1 depicts the determination of laminate properties based on known constituent properties. The top part depicts the finite element analysis which provides the structural response at the laminate level. And, the right part shows the decomposition of the structural response at the constituent level. Finally, the bottom left part shows the updating of constituent material properties. This is accomplished by using (1) the multifactor-interaction equation in METCAN, (2) input parameters from tables II and III, and (3) calculated constituent stresses in selected regions as shown in figure 2 . 
HITCAN accomplishes the approach shown in figure 1 by calling upon (1) the model (mesh) generator, (2) the finite element code MHOST, and (3) the multilevel material behavior code METCAN. HITCAN manages the flow of information between MHOST and METCAN. It also serves the function of transforming the input-output between MHOST and METCAN to the desired form. The flow-chart in figure 3 shows the major computational procedure steps, in the order in which they are executed by the code. A brief description of the approach follows.

Step 1. Finite Element Model Generation

HITCAN generates a finite element model of the structure, based on coordinates of a few representative points. This is accomplished by interpolators coded in HITCAN. The temperature and pressure loadings are also input only at the representative points, to be interpolated for the rest of the model automatically by the code. Notice that the finite elements are at the laminate level but the material properties input in step 1 are at the constituent materials level.

Step 2. Constituent Material Property Generation

Based on reference constituent material properties available at the end of Step 1, METCAN generates constituent material properties including an interactive dependence on parameters such as temperature, stress, and stress rate before the next load step (see multifactor-interaction equations in ref. 3 ). This step is illustrated through the item, $A$, marked in boxed letter in figure 1.

\section{Step 3. Laminate Material Property Generation}

The material properties available at the end of step 2 need to be converted to those at the laminate level before conducting the finite element analysis. METCAN accomplishes step 3 by using micro- and macro-mechanics theories. This step is illustrated through items, $B$ and $C$, marked in boxed letters in figure 1.

\section{Step 4. Global structural Response}

All information necessary for the global finite element structural analysis becomes available at the end of step 3. MHOST accomplishes step 4 by calculating the structural response at the laminate level. This step is illustrated by the item, $D$, marked in boxed letter in figure 1 .

\section{Step 5. Constituent Structural Response}

Based on laminate structural response calculated in step 4, METCAN calculates the ply and congtituent level structural response using macro- and micro-mechanics theories, shown by items, $E$ and F, marked in boxed letters in figure 1.

\section{Step 6. Updating of Constituent Material Properties}

Since the constituent material properties depend on calculated constituent stress response which, in turn, depends on constituent material properties, an iterative 
scheme is used to obtain both the structural response and material properties which are compatible with each other. For a specific load step, the ply level response (strains) and structure level response (strains at nodes) are compared at the end of each iteration with the response at the end of the previous iteration. Notice that the ply level response is in the local materials coordinate system whereas the structure level response is in the global structural coordinate system. Figure 1 shows both of these coordinate systems. If the difference in the response for two consecutive iterations is within a predetermined tolerance level, it is assumed that the solution has reached a satisfactory level of convergence. This step is illustrated through a diamond-shaped block in figure 3 .

\section{Additional Capabilities}

Additional features such as fiber degradation and fabrication-induced stresses have been incorporated in the computational procedure. Fiber degradation is accounted for by decreasing the diameter of the fiber based on a user specified fraction of the original fiber diameter. This creates an interphase, of a specified thickness, between the fiber and matrix. The stresses during fabrication are calculated by defining the cool down process from the consolidation temperature to reference temperature as a specified load history added prior to the application of actual loads.

\section{HITCAN DEMONSTRATION}

HITCAN capabilities have been demonstrated through illustrative examples for five types of structures (ref. 1). Four of these represent basic geometries that are the building blocks of most structures of practical interest. They are beam, plate, ring, and curved panel. The fifth one is a built-up structure. several types of analyses, marked "tested" in italics in table $I$, were conducted for each type of structure. The analyses tested include static, buckling, modal, and nonlinear load stepplng. The load stepplng analysis consists of multistep static analysis with material properties updated at each step. All analyses were based on multilevel interactive material behavior. The sensitivity of structural response to various parameters was determined by repeating the load stepping analysis for various forms of multifactor-interaction constitutive models, for various ply orientations, and for various additional features including fiber degradation and fabrication-induced stresses. Reference 1 includes results for all these cases. The results for buckling, load stepping, and sensitivities analysis for the built-up structure are summarized herein. These results include all the responses required to assess the adequacy of a design, in general.

The geometry and loading conditions for the built-up structure are shown in figure 4. The built-up structure is made of two horizontal plates at top and bottom, joined by three vertical spars. The material chosen is SiC/Ti 15-3-3-3 (where SiC stands for silicon Carbide fiber and Ti-15-3-3-3 for an alloy of titanium with 15 percent Vanadium, 3 percent Aluminum, 3 percent Chromium, and 3 percent Tin). This materlal was chogen because it has already received wide recognition as a viable candidate for some of the high temperature applications associated with the National Aerospace Plane (NASP). The material properties of SiC fiber and Ti 15-3-3-3 matrix, in the unstressed reference state, are given in table II. In all cases, the reference temperature was $70^{\circ} \mathrm{F}$ both for material properties and thermal loading, the fiber volume ratio was 0.4 , the laminate consisted of 4-ply layers top surface, 
2-layers bottom surface, and 4-layer spars. The finite element was a 4-node isoparametric shell element with six degrees of freedom per node, and the exponents used for the multifactor-interaction constitutive material behavior model are given in table III. The ply orientations were chosen to be a (90/0), top surface, (90), bottom surface, and $4(0)$ spars. The first ply is at the top surface and the last ply is at the bottom surface. The ply orientation of $0^{\circ}$ means fibers oriented in the $x$-direction. Other, i.e., nonzero, orientations represent fibers oriented at the specified angle of rotation with respect to $x$-axis towards the $y-a x i s$. The ply orientations for the top and bottom plates and spars are shown in $f$ igure 5 .

The buckling results are shown in figure 6 for the three different load conditions (mechanical load, mechanical load with 10 percent fiber diameter degradation, and combined thermal and mechanical loads). The results demonstrate the HITCAN capability for this type of thermostructural analysis. They indicate that temperature degrades the buckling resistance of this built-up structure by almost 10 percent.

The results for the load stepping analysis are summarized in figure 7 where two natural frequencies, the displacement at a select point and the stresses in a specific ply as well as in the constituents (regions, $A, B$, and $C$ are depicted in fig. 2) are shown. A wealth of information is in this figure: (1) the two frequencies are relatively close together and degrade with degrading material properties, (2) the displacement increases slightly nonlinearly with linearly increasing load, (3) the stresses in the constituent remain mainly nonlinear except for the interphase where fallure (transverse stress) is indicated beyond load step 1 .

The collective results in figure 7 demonstrate the versatility and detail depth that the HITCAN capabilities provide for the thermal/structural analysis of aerospace structures. Although results are not shown here for actively cooled hot structures, it is apparent that they can be handled once the coolant pressure and temperature profiles are known.

The effects of fiber degradation, fabrication-induced stresses, and material behavior (sensitivity analysis) on displacement and ply stresses at load step 3 are summarized in figure 8. The fabrication-induced stresses and temperature have generally the most effect on ply stregses and displacements for the specific built-up structure. The temperature and applied load stress effects are graphically illustrated in figure 9. As can be seen, the temperature effect dominates for the sample problem shown here.

\section{CONCLUSIONS}

The capabilities of a high temperature composites analyzer code, HITCAN, have been demonstrated. HITCAN was developed for performing most of the typical structural analysis tasks for designing with multilayered metal matrix composites. It employs multifactor-interaction constitutive material behavior models. It includes additional features such as fiber degradation and fabrication-induced stresses. Because of the multilevel analysis approach, HITCAN has the utility for studying the influence of individual constituent in-situ behavior on global structural response. Several features of HITCAN have been demonstrated through a specific example problem. These features make HITCAN a powerful tool for analyzing/ designing metal matrix composites for actively cooled hot aeropropulsion structures. 


\section{REFERENCES}

1. Singhal, S.N., Lackney, J.J., Chamis, C.C., and Murthy, P.L.N., 1990, "Demonstration of Capabilities of High Temperature Composites Analyzer Code HITCAN," NASA TM-102560.

2. Nakazawa, S., 1989, "The MHOST Finite Element Program: 3-D Inelastic Analysis Methods for Hot Section Components. Volume II - User's Manual," NASA CR-182235.

3. Murthy, P.L.N. and Hopkins, D.A., 1988, "Metal Matrix Composites Analyzer: METCAN User's Guide, NASA Report (in Draft Form).

4. Alello, R.A. and Chamis, C.C., 1989, "Composite Blade Structural Analyzer (COBSTRAN) Theoretical/Programmer's Manual," NASA TM-101958. 
TABLE I. - HITCAN CAPABILITIES FOR COMPOSITE MATERIALS

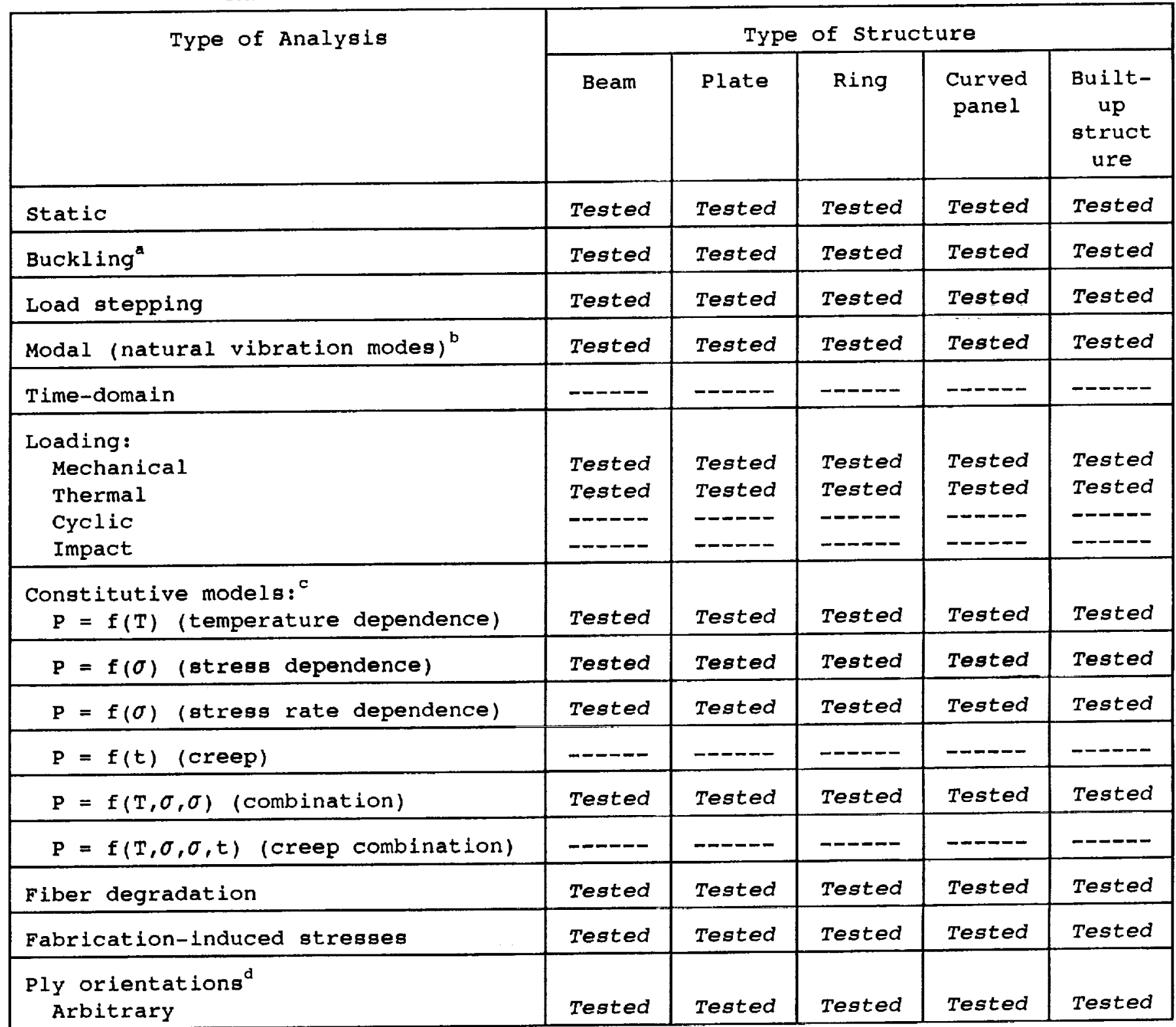

Tested 1 buckling mode

bested 4 vibration modes

${ }^{C}$ Constitutive models: notation

P: Material properties

T: Temperature

$\sigma:$ stress

$\sigma:$ stresg rate

$t:$ Time

dested 3-ply orientations

Unsymmetric: (0/ $\pm 45 / 90)$

symmetric: $(0 / 45)_{\mathrm{s}}$

Balanced: $\quad(0 / 90)_{B}$ 
TABLE II. - CONSTITUENT MATERIAL PROPERTIES

AT UNSTRESSED REFERENCE TEMPERATURE

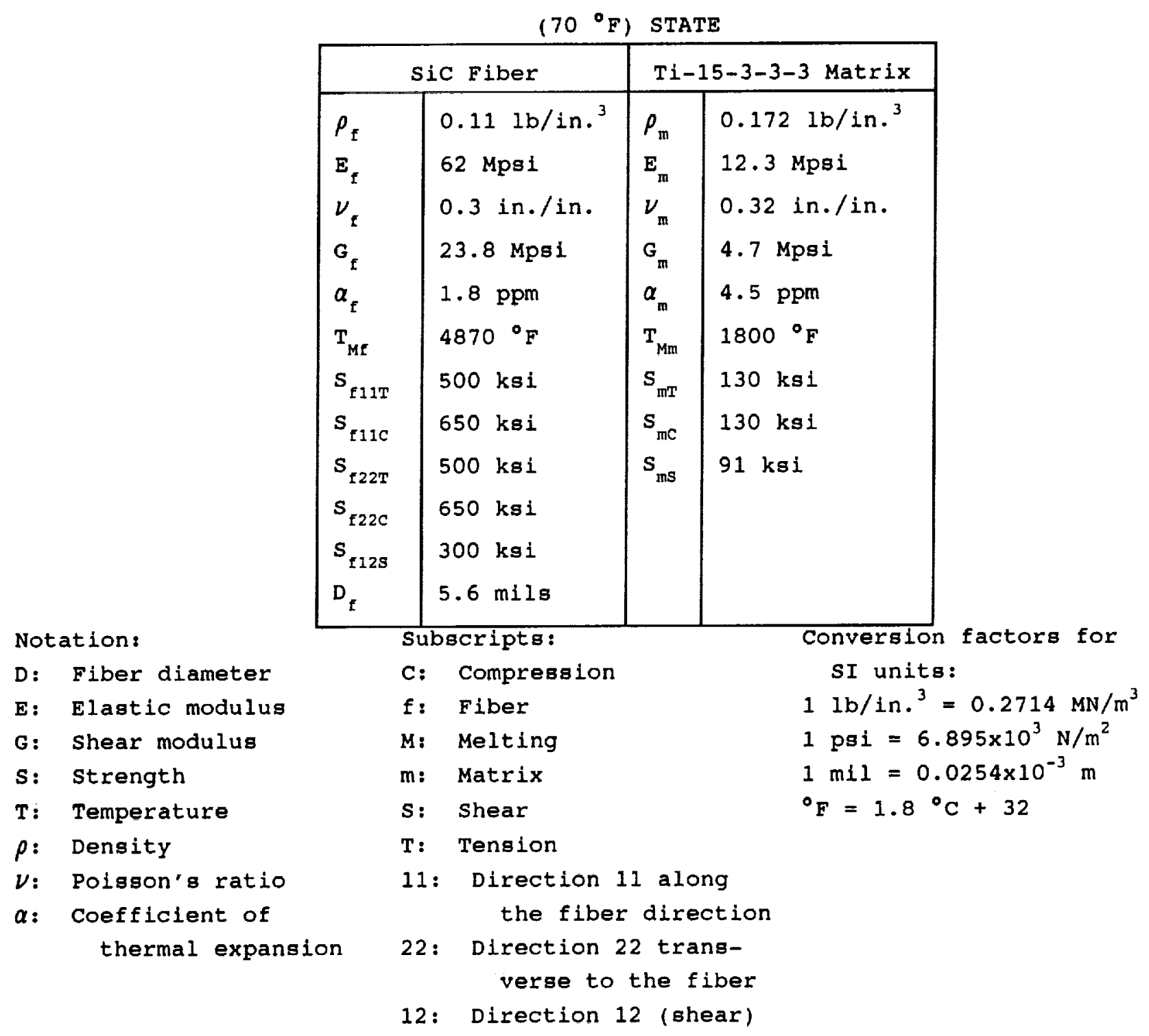


TABLE III. - EXPONENTS USED FOR MULTIFACTOR-INTERACTIVE

MATERIAL BEHAVIOR MODELS

[Material: SiC/Ti-15-3-3-3.]

\begin{tabular}{|l|c|c|c|c|c|c|}
\hline \multirow{2}{*}{$\begin{array}{l}\text { Material } \\
\text { properties }\end{array}$} & \multicolumn{3}{|c|}{ Factors affecting material properties } \\
\cline { 2 - 7 } & \multicolumn{2}{c|}{ Temperature } & \multicolumn{2}{c|}{ Stress } & \multicolumn{2}{c|}{ Stress rate } \\
\cline { 2 - 7 } & Matrix & Fiber & Matrix & Fiber & Matrix & Fiber \\
\hline $\begin{array}{l}\text { Moduli } \\
\text { Poisson's } \\
\text { ratios } \\
\text { Strengths }\end{array}$ & 0.5 & 0.25 & 0.5 & 0.25 & 0.5 & 0.25 \\
$\begin{array}{l}\text { Thermal } \\
\begin{array}{c}\text { expansion } \\
\text { coefficients }\end{array}\end{array}$ & .5 & .25 & .5 & .25 & .5 & .25 \\
\hline
\end{tabular}

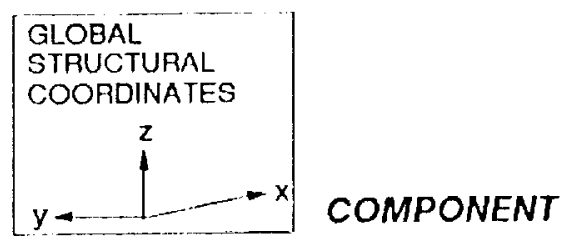

[D] FINITE ELEMENT $\Rightarrow \Rightarrow$ FINITE ELEMENT [D] GLOBAL STRUCTURAL $\cong \equiv$ ANALYSIS

\section{LAMINATE}

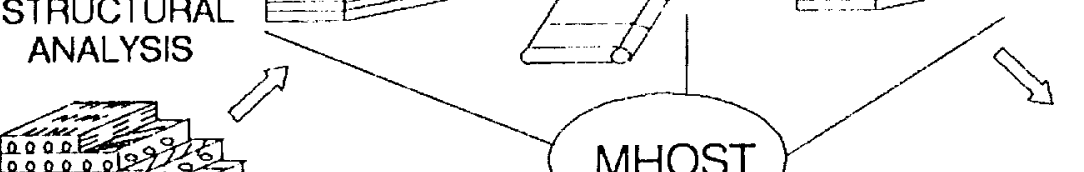

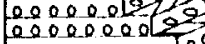

$E=\equiv$

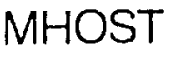

$E E \equiv$

STRUCTURAL ANALYSIS
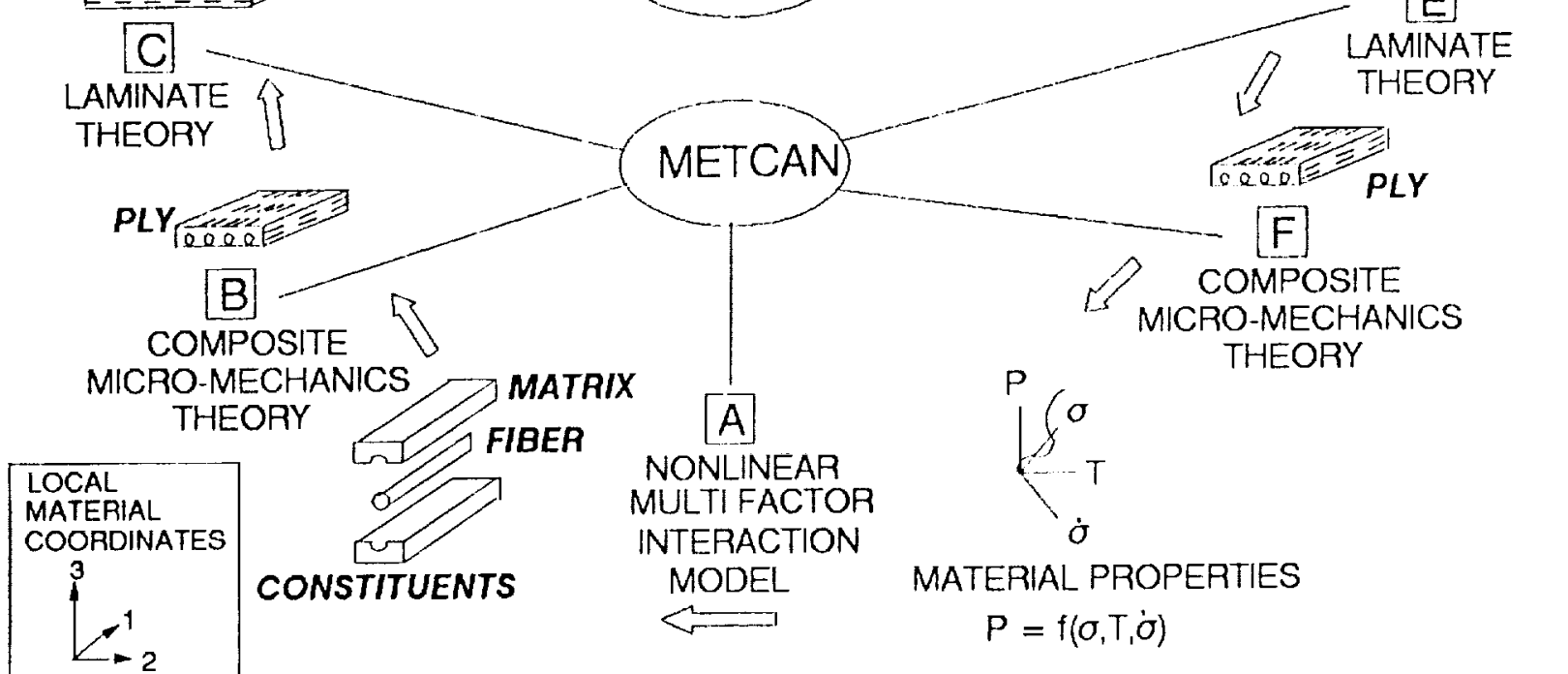

MATRIX

RIX

COMPOSITE MICAO-MECHANICS THEORY

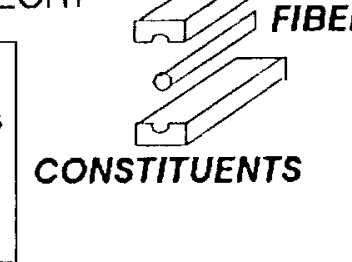

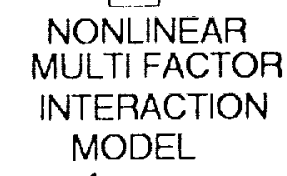

$<$ SQ0.E PLY

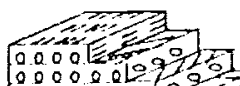
00000.0975 00000002200 LAMINATE LAMINATE - F COMPOSITE MICRO-MECHANICS THEORY

Figure 1.-HITCAN: An integrated approach for high temperature composite structural analysis. 
A: Matrix

B: Matrix and Interphase

C: Matrix, Fiber, and Interphase

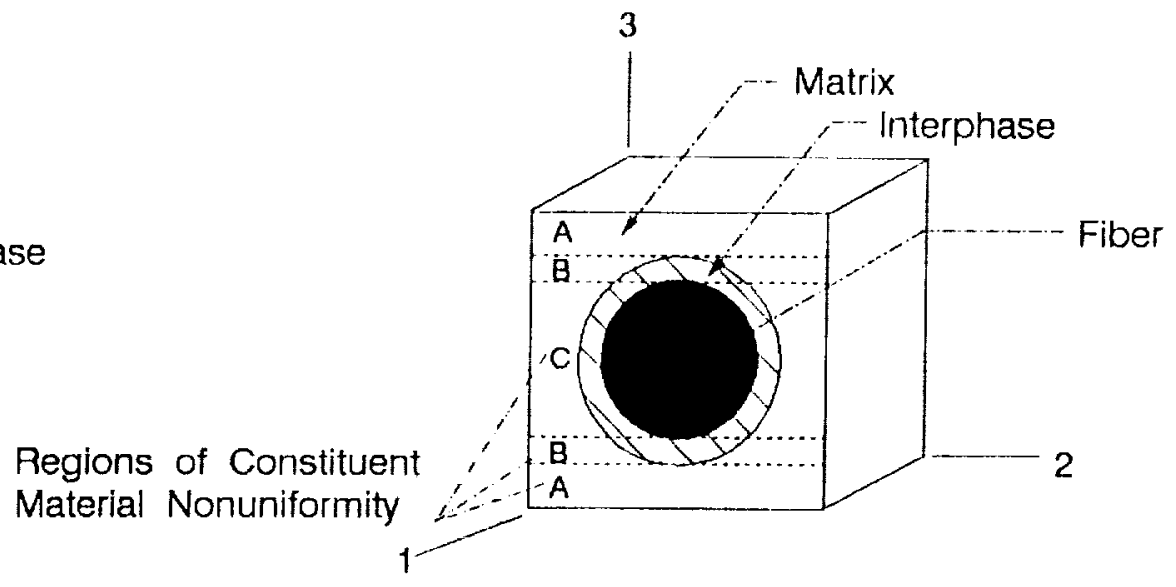

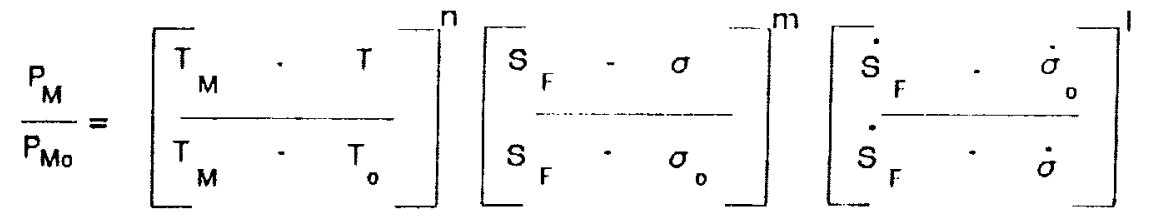

\section{Notatlon:}

P - property of interest

$T$ - temperature

S, $\sigma$ - stress

$\bar{s}, \bar{\sigma}$ - stress rate
Subscrlpts and exponents:

o - relerence state

$M \cdot$ melting

F - iracture

$n, m, l$ - empirical constants

Figure 2.-Schematics for regions of constituent material nonunilormity and nonlinear multi-factor interaction equation. 


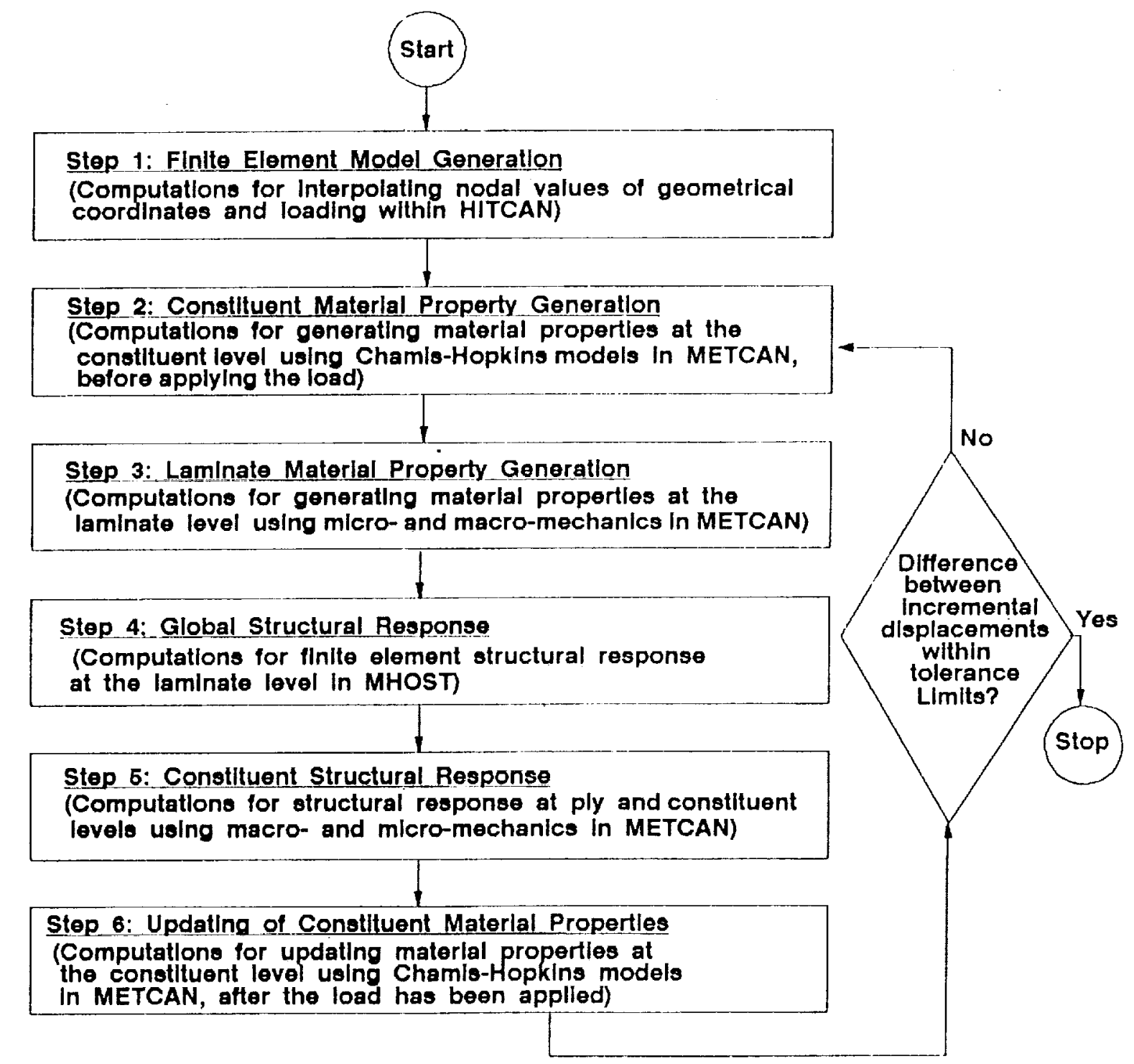

Figure 3.-Flow chart for HITCAN computational procedure. 
BOTTOM SUPPORTED BUILT-UP STRUCTURE UNDER BENDING AND UNIFORM TEMPERATURE LOADINGS FOR (SIC/TI-15-3-3-3, TOP: $[90,0]_{\text {, }}$ BOTTOM: $[90]_{s}$, SPARS:4[0] $]_{s}$; 0.4 FIBER VOLUME RATIO

\section{GEOMETRY}

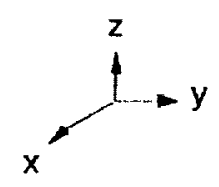

Conversion Factors for SI units:

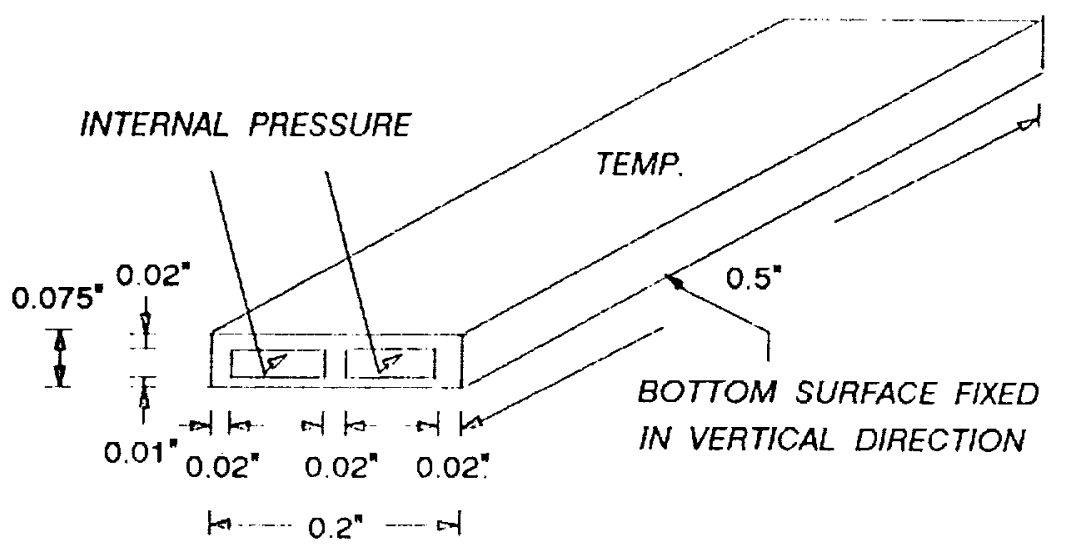

1 in $=0.0254 \mathrm{~m}$

$1 \mathrm{psi}=6.895 \times 10^{3} \mathrm{~N} / \mathrm{m}^{2}$

${ }^{\circ} \mathrm{F}=1.8^{\circ} \mathrm{C}+32$

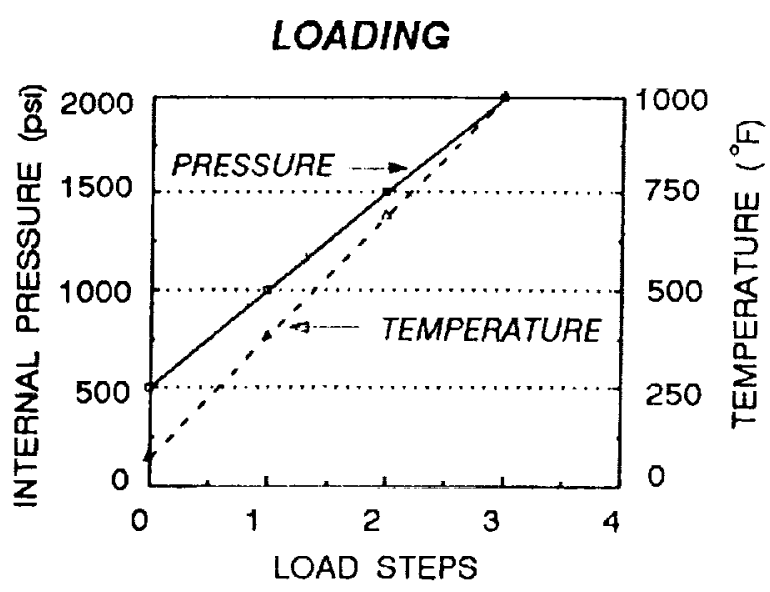

Figure 4.-Geometry and loading for built-up structure. 
TOP PLATE OF THE PANEL

(PLY LAY-UP IN Z - DIRECTION)

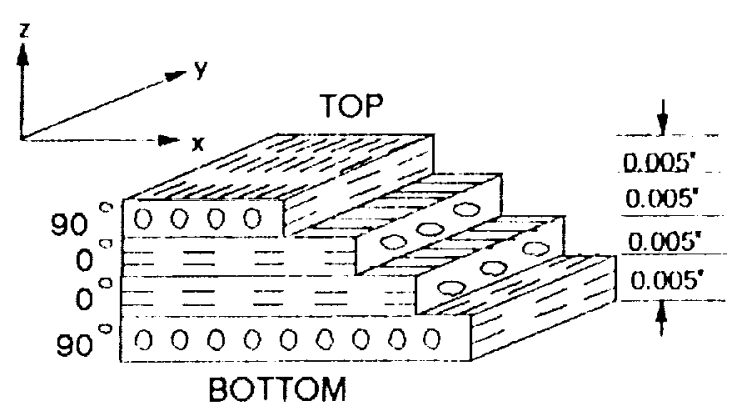

BOTTOM PLATE OF THE PANEL

(PLY LAY-UP IN Z - DIRECTION)

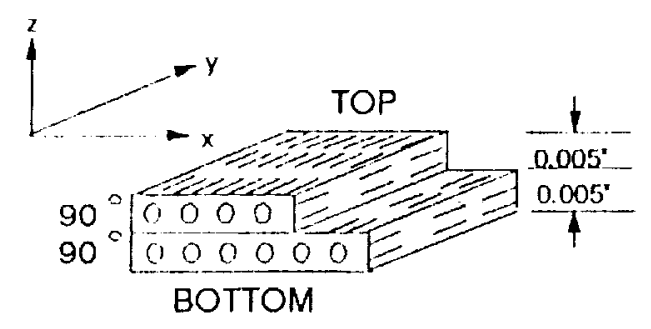

\section{SPARS}

(PLY LAY-UP IN Y-DIRECTION)

Conversion Factors for SI unils: 1 in $=0.0254 \mathrm{~m}$

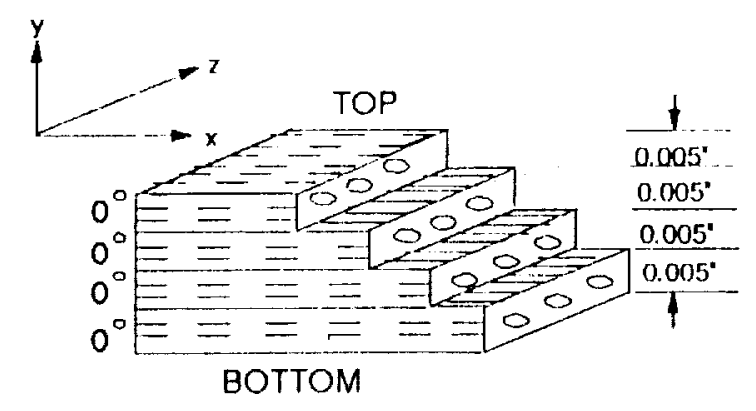

Figure 5.-Ply lay-ups for the built-up structure. 
SIMPLY SUPPORTED-FREE BUILT-UP STRUCTURE UNDER COMPRESSIVE AXIAL AND UNIFORM TEMPERATURE LOADINGS FOR (SIC/TI-16-3-3-3, TOP:[90,0], BOTTOM:[90], SPARS:4[0] $]_{\mathrm{s}}$; 0.4 FIBER VOLUME RATIO

\section{GEOMETRY AND LOADING FORCE}

Conversion Factors for SI unlls:

1 in $=0.0254 \mathrm{~m}$

$1 \mathrm{lb} / \mathrm{in}=175.12 \mathrm{~N} / \mathrm{m}$

${ }^{\circ} \mathrm{F}=1.8^{\circ} \mathrm{C}+32$

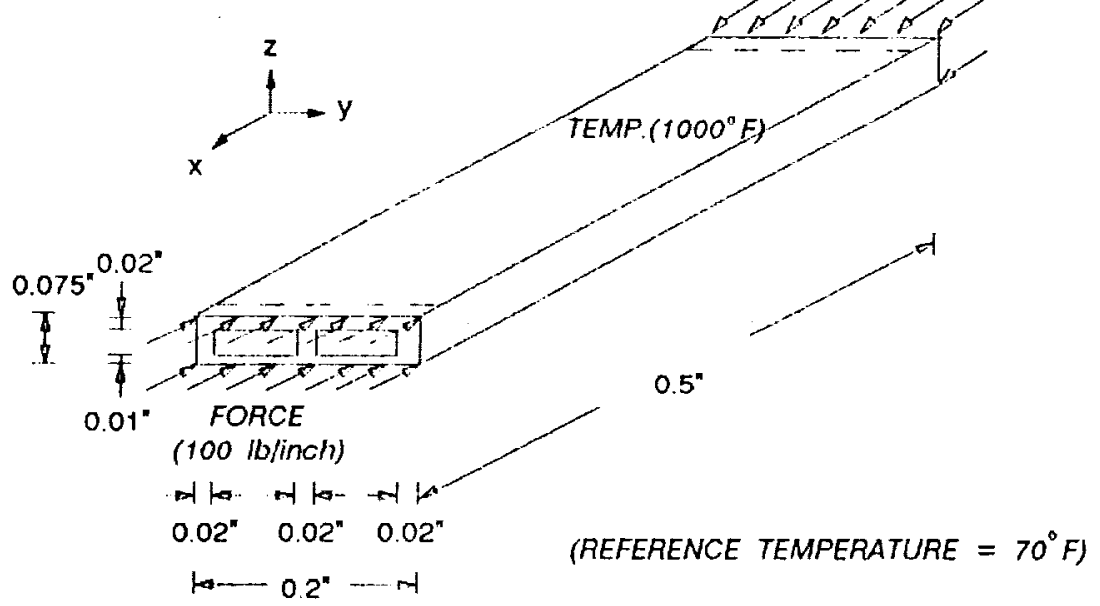

\section{CRITICAL BUCKLING FORCE}

(i) UNDER MECHANICAL LOADING ONLY $=2950 \mathrm{lb} /$ inch

(ii) WITH FIBER DEGRADATION, UNDER MECHANICAL LOADING ONLY $=2850 \mathrm{lb} / \mathrm{inch}$

(iii) UNDER THERMO-MECHANICAL LOADING $=2720 \mathrm{lb} /$ inch

Figure 6.-Buckling analysis for built-up structure under thermo-mechanical loading. 
BOTTOM SUPPORTED BUILT-UP STRUCTURE UNDER BENDING AND UNIFORM TEMPERATURE LOADINGS FOR (SIC/TI-16-3-3-3, TOP:[90,0], BOTTOM:[90], SPARS:4[0] $]_{s}$ ); 0.4 FIBER VOLUME RATIO

GEOMETRY

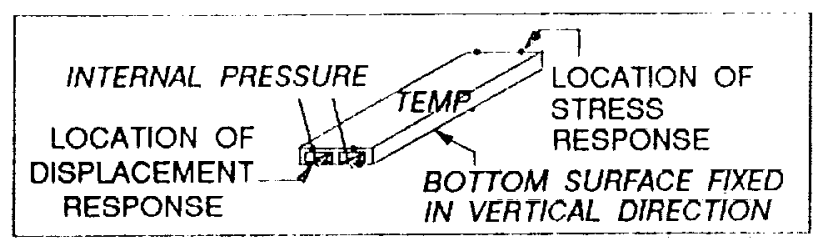

LOADING

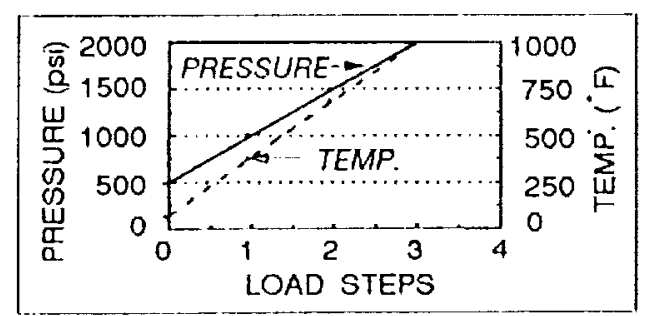

DISPLACEMENTS, BOTTOM END EDGE

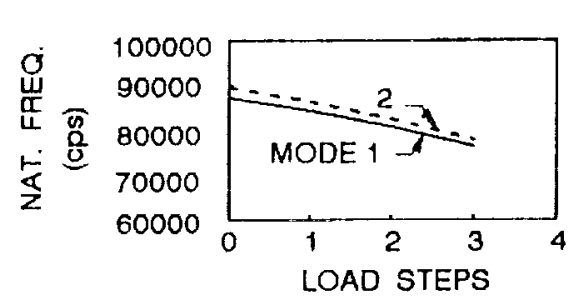

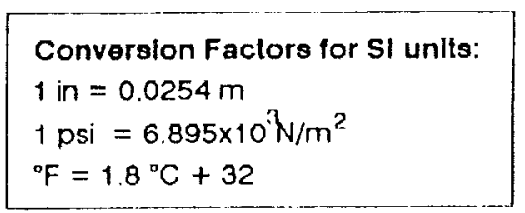

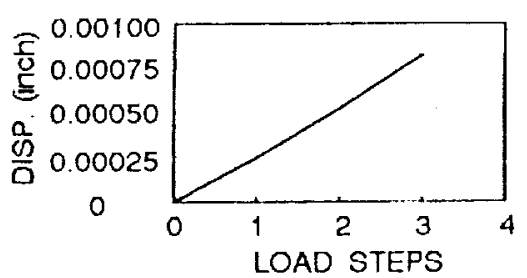

STRESSES, TOP END EDGE, PLY 1
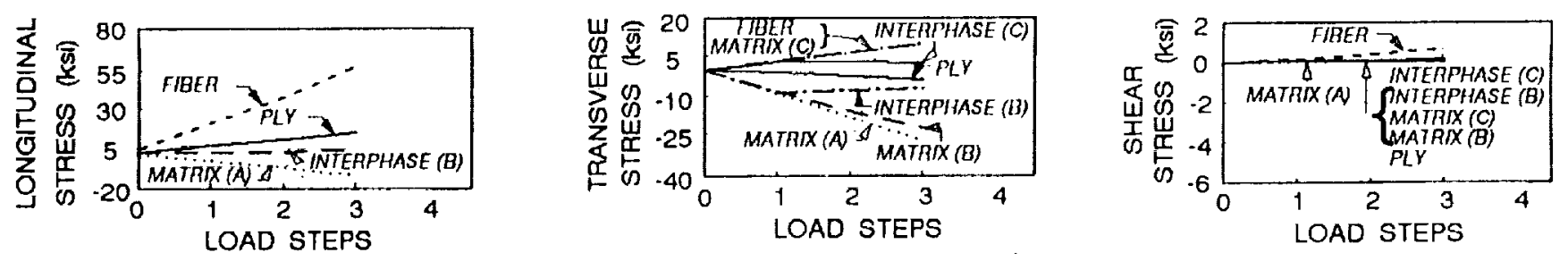

Figure 7.-Base case results for built-up structure. 


\section{BOTTOM SUPPORTED BUILT-UP STRUCTURE UNDER BENDING AND UNIFORM TEMPERATURE LOADINGS FOR (SIC/TI-15-3-3-3, TOP:[90,0], BOTTOM:[90], SPARS:4[0] $\left.]_{s}\right) ; \quad 0.4$ FIBER VOLUME RATIO}

\section{EFFECT OF MATERIAL PROPERTY VARIATIONS ON DISPLACEMENT AT BOTTOM END EDGE}

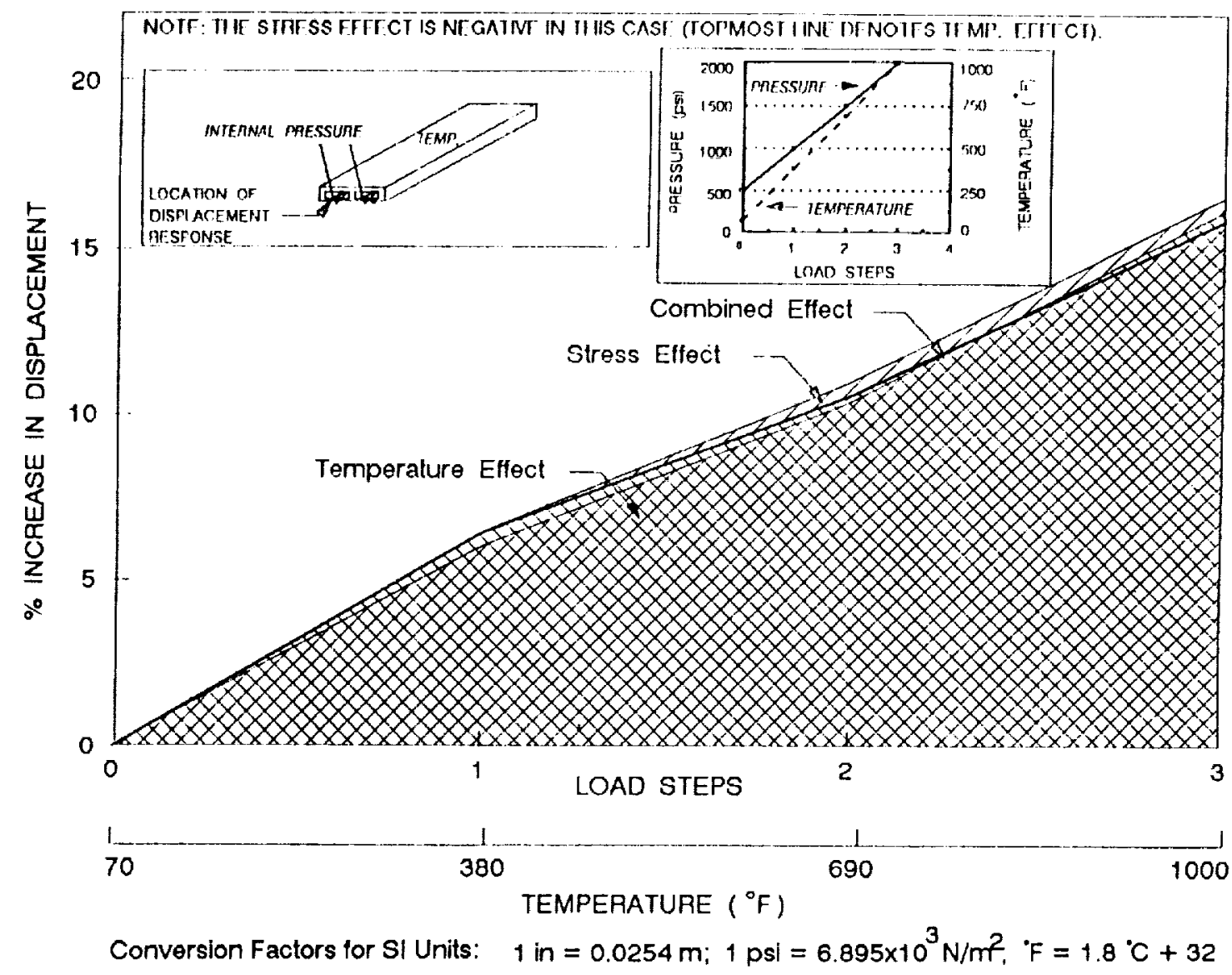

Figure 8.-Sensitivity analysis for built-up structure. 
BOTTOM SUPPORTED BUILT-UP STRUCTURE UNDER BENDING AND UNIFORM TEMPERATURE LOADINGS FOR (SIC/TI-15-3-3-3, TOP: $[90,0]$, BOTTOM: $[90]_{\mathrm{s}}$, SPARS: $\left.4[0]_{s}\right)$; 0.4 FIBER VOLUME RATIO

\section{RESPONSE: AT LOAD STEP 3}

\section{GEOMETRY AND LOADING}
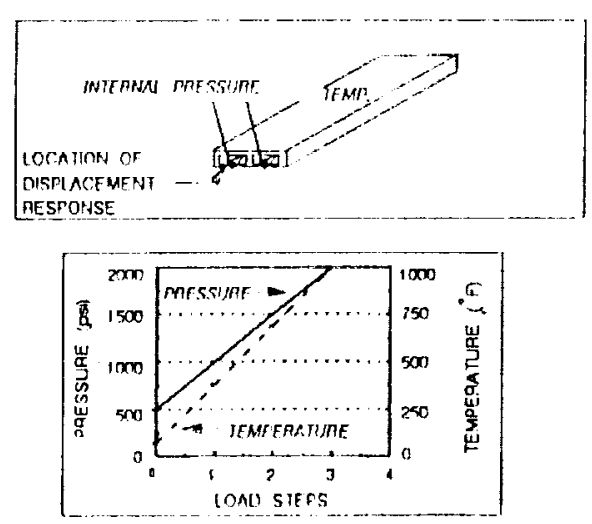

CONSTITUTIVE RELATIONSHIPS

(NONLINEAR MULTI-FACTOR INTERACTION MODEL)

\begin{tabular}{|c|c|c|c|c|}
\hline \multirow[t]{2}{*}{ RELATIONSHIP } & \multirow{2}{*}{$\begin{array}{l}\text { DISP } \\
\text { [BIOIIOM } \\
\text { TND) } \\
\text { IDGIJ } \\
\text { (incli) }\end{array}$} & \multicolumn{3}{|c|}{$\begin{array}{l}\text { STAESSES. PLY } 1 \\
\text { [TOP END EDGE] (ksi) }\end{array}$} \\
\hline & & conchitgomial & IMAISVERSE & SHEAR \\
\hline$P=$ CONSTANT & 0.000710 & 15.2 & -2.6 & 0.1 \\
\hline $\begin{array}{l}P=T(T) \\
\text { TEMN. DLPLNI)FNCE }\end{array}$ & 0.000828 & 16.4 & -3.6 & 1.0 \\
\hline $\begin{array}{l}P=(\sigma) \\
\text { SIHESS DEICNDENCE }\end{array}$ & 0.000707 & 14.3 & -2.4 & 0.1 \\
\hline $\begin{array}{l}\vec{P}=f(\dot{\sigma}) \\
\text { SUII SS NAIE DIPENDFNCE }\end{array}$ & 0.000710 & 15.2 & -2.6 & 0.1 \\
\hline $\begin{array}{l}P=f(T, \sigma, \dot{\sigma}) \\
\text { COMUIPJAIION }\end{array}$ & 0.000823 & 15.2 & -3.3 & 0.1 \\
\hline
\end{tabular}

NOTATION

$P=$ MATERIAL PROPERTY $T=$ TEMPERATURE

$\sigma=$ STRESS $\dot{\sigma}=$ STRESS RATE

\section{FABRICATION-INDUCED STRESSES}

\begin{tabular}{|c|c|c|c|c|}
\hline $\begin{array}{c}\text { FABRICATION- } \\
\text { INDUCED } \\
\text { STRESSES }\end{array}$ & $\begin{array}{c}\text { DISP. } \\
\text { [BOTIOM } \\
\text { END } \\
\text { EDGF] } \\
\text { (inch) }\end{array}$ & \multicolumn{3}{|c|}{ STRESSES, PLY } \\
[TOP END EDGE] & (ksi) \\
\hline NO & 0.000823 & 15.2 & -3.3 & 0.1 \\
\hline YES & 0.000420 & 12.2 & 0.5 & 0.02 \\
\hline
\end{tabular}

FIBER DEGRADATION

\begin{tabular}{|c|c|c|c|c|}
\hline \multirow{2}{*}{ DEGRADATION } & \multirow{2}{*}{$\begin{array}{l}\text { DISP. } \\
\text { [BOTTOM } \\
\text { END } \\
\text { FUGEI } \\
\text { (inch) }\end{array}$} & \multicolumn{2}{|c|}{$\begin{array}{l}\text { STRESSES, PLY } \\
\text { [TOP END EDGE] }\end{array}$} & \multirow{2}{*}{$\begin{array}{l}1 \\
\text { (ksi) } \\
\text { SMEAT }\end{array}$} \\
\hline & & T.ONGTUDINAL & TRANSVERSE & \\
\hline NO & 0.000823 & 15.2 & -3.3 & 0.1 \\
\hline YES & 0.000886 & 14.4 & -2.6 & 0.1 \\
\hline
\end{tabular}

Conversion Faclors for SI Units: $\quad 1$ in $=0.0254 \mathrm{~m} ; 1 \mathrm{psi}=6.895 \times 10^{3} \mathrm{~N} / \mathrm{n}^{2},{ }^{\prime} \mathrm{F}=1.8^{\circ} \mathrm{C}+32$

Figure 9.-Sensitivity to constitutive models for built-up structure. 


\begin{tabular}{|c|c|c|c|c|}
\hline \multicolumn{5}{|c|}{ Report Documentation Page } \\
\hline $\begin{array}{l}\text { 1. Report No. } \\
\text { NASA TM }-103750\end{array}$ & \multicolumn{2}{|c|}{ 2. Government Accession No. } & \multicolumn{2}{|c|}{ 3. Recipient's Catalog No. } \\
\hline \multicolumn{3}{|c|}{$\begin{array}{l}\text { 4. Title and Subtitle } \\
\text { HITCAN for Actively Cooled Hot-Composite Thermostructural Analysis }\end{array}$} & \multicolumn{2}{|l|}{ 5. Report Date } \\
\hline & & & \multicolumn{2}{|c|}{ 6. Periorming Organization Code } \\
\hline \multicolumn{3}{|c|}{$\begin{array}{l}\text { 7. Author(s) } \\
\text { C.C. Chamis, P.L.N. Murthy, S.N. Singhal, and J.J. Lackney }\end{array}$} & \multicolumn{2}{|c|}{$\begin{array}{l}\text { 8. Performing Organization Report No. } \\
\text { E- } 6002\end{array}$} \\
\hline & & & \multicolumn{2}{|c|}{$\begin{array}{l}\text { 10. Work Unit No. } \\
763-01-41\end{array}$} \\
\hline \multirow{2}{*}{\multicolumn{3}{|c|}{$\begin{array}{l}\text { 9. Performing Organization Name and Address } \\
\text { National Aeronautics and Space Administration } \\
\text { Lewis Research Center } \\
\text { Cleveland, Ohio } 44135 \text { - } 3191\end{array}$}} & \multicolumn{2}{|c|}{ 11. Contract or Grant No. } \\
\hline & & & \multirow{2}{*}{\multicolumn{2}{|c|}{$\begin{array}{l}\text { 13. Type of Report and Period Covered } \\
\text { Technical Memorandum }\end{array}$}} \\
\hline \multirow{2}{*}{\multicolumn{3}{|c|}{$\begin{array}{l}\text { 12. Sponsoring Agency Name and Address } \\
\text { National Aeronautics and Space Administration } \\
\text { Washington, D.C. } 20546-0001\end{array}$}} & & \\
\hline & & & \multicolumn{2}{|c|}{ 14. Sponsoring Agency Code } \\
\hline \multicolumn{5}{|c|}{$\begin{array}{l}\text { 15. Supplementary Noles } \\
\text { Prepared for the 36th International Gas Turbine and Aeroengine Congress and Exposition sponsored by the American } \\
\text { Society of Mechanical Engineers, Orlando, Florida, June 3-6, 1991. C.C. Chamis and P.L.N. Murthy, NASA Lewis } \\
\text { Research Center; S.N. Singhal and J.J. Lackney, Sverdrup Technology, Inc. Lewis Research Center Group, } 2001 \\
\text { Aerospace Parkway, Brook Park, Ohio 44142. Responsible person, C.C. Chamis, (216) 433-3252. }\end{array}$} \\
\hline \multicolumn{5}{|c|}{$\begin{array}{l}\text { 16. Abstract } \\
\text { A computer code, HITCAN (HIgh Temperature Composite ANalyzer) has been developed to analyze/design hot metal } \\
\text { matrix composite structures. HITCAN is a general purpose code for predicting the global structural and local stress-strain } \\
\text { response of multilayered (arbitrarily oriented) metal mattix structures both at the constituent (fiber, matrix, and interphase) } \\
\text { and the structure level and including the fabrication process effects. The thermomechanical properties of the constituents } \\
\text { are considered to be nonlinearly dependent on several parameters including temperature, stress, and stress rate. The } \\
\text { computational procedure employs an incremental iterative nonlinear approach utilizing a multifactor-interaction material } \\
\text { behavior model, i.e., the material properties are expressed in terms of a product of several factors that affect the properties: } \\
\text { HITCAN structural analysis capabilities (static, load stepping - a multistep static analysis with material properties updated } \\
\text { at each step -, modal, and buckling) for cooled hot structures are demonstrated through a specific example problem. }\end{array}$} \\
\hline \multicolumn{2}{|c|}{$\begin{array}{l}\text { 17. Key Words (Suggested by Author(s)) } \\
\text { Buckling; Composite mechanics; Computer codes; } \\
\text { Fabrication stresses; Fiber composites; Metal matrix; Finite } \\
\text { element analysis; Global response; High temperature } \\
\text { composites; Interphase; Interphase degradation; Laminate } \\
\text { analysis; Load stepping; Local response; Material } \\
\text { nonlinearities; Mechanical properties; Microstresses; } \\
\text { Micromechanics; Modal analysis; Nonlinear behavior; Stress } \\
\text { analysis; Structural analysis; Thermal properties; } \\
\text { Thermomechanical analysis; Vibration frequencies }\end{array}$} & \multicolumn{3}{|c|}{$\begin{array}{l}\text { 18. Distribution Statement } \\
\text { Unclassified - Unlimited } \\
\text { Subject Category } 39\end{array}$} \\
\hline 19. Security Classil. (of the report) & 20. Security Classif, fof t & is page) & 21. No. of pages & 22. Price" \\
\hline Unclassified & Uncla: & sified & 18 & $\mathrm{~A} 03$ \\
\hline
\end{tabular}

